\title{
Cardiovascular progenitor cells and tissue plasticity are reduced in a myocardium affected by Becker muscular dystrophy
}

Martin Pes1 ${ }^{1,2,3}$, Sarka Jelinkova ${ }^{1,2}$, Guido Caluori ${ }^{2,4}$, Maria Holicka ${ }^{5}$, Jan Krejci ${ }^{3}$, Petr Nemec ${ }^{6}$, Aneta Kohutova ${ }^{1,2}$, Vita Zampachova ${ }^{7}$, Petr Dvorak ${ }^{1}$ and Vladimir Rotrekl ${ }^{1,2^{*}}$

\begin{abstract}
We describe the association of Becker muscular dystrophy (BMD) derived heart failure with the impairment of tissue homeostasis and remodeling capabilities of the affected heart tissue. We report that BMD heart failure is associated with a significantly decreased number of cardiovascular progenitor cells, reduced cardiac fibroblast migration, and ex vivo survival.

Background: Becker muscular dystrophy belongs to a class of genetically inherited dystrophin deficiencies. It affects male patients and results in progressive skeletal muscle degeneration and dilated cardiomyopathy leading to heart failure. It is a relatively mild form of dystrophin deficiency, which allows patients to be on a heart transplant list. In this unique situation, the explanted heart is a rare opportunity to study the degenerative process of dystrophin-deficient cardiac tissue. Heart tissue was excised, dissociated, and analyzed. The fractional content of c$\mathrm{kit}^{+} / \mathrm{CD} 45^{-}$cardiovascular progenitor cells (CVPCs) and cardiac fibroblast migration were compared to control samples of atrial tissue. Control tissue was obtained from the hearts of healthy organ donor's during heart transplantation procedures.
\end{abstract}

Results: We report significantly decreased CVPCs (c-kit $\left.{ }^{+} / \mathrm{CD}^{-} 5^{-}\right)$throughout the heart tissue of a BMD patient, and reduced numbers of phase-bright cells presenting c-kit positivity in the dystrophin-deficient cultured explants. In addition, ex vivo CVPCs survival and cardiac fibroblasts migration were significantly reduced, suggesting reduced homeostatic support and irreversible tissue remodeling.

Conclusions: Our findings associate genetically derived heart failure in a dystrophin-deficient patient with decreased c-kit ${ }^{+} / \mathrm{CD} 45^{-}$CVPCs and their resilience, possibly hinting at a lack of cardioprotective capability and/or reduced homeostatic support. This also correlates with reduced plasticity of the explanted cardiac tissue, related to the process of irreversible remodeling in the BMD patient's heart.

Keywords: Becker muscular dystrophy, Dystrophin, Cardiovascular progenitor cells, C-kit, Cardiomyopathy, Heart failure

\section{Background}

Dystrophinopathies are a class of inherited X-linked genetic disorders that impair the proper synthesis of dystrophin, a scaffolding protein found in skeletal and cardiac muscle [1]. More than $70 \%$ of patients suffering from Becker muscular dystrophy (BMD), a mild form of

\footnotetext{
* Correspondence: vrotrekl@med.muni.cz

'Department of Biology, Faculty of Medicine, Masaryk University, Kamenice 5, Brno 62500, Czech Republic

${ }^{2}$ International Clinical Research Center, (ICRC), St. Anne's University Hospital, Pekarska 53, Brno 65691, Czech Republic

Full list of author information is available at the end of the article
}

dystrophin deficiency, are diagnosed with dilated cardiomyopathy $(\mathrm{DCM})[2,3]$, which is uncorrelated with skeletal muscle degeneration [4]. Heart failure is the most common cause of death in those with BMD [5], and patients are, in individual cases, referred for heart transplantation [6].

The cellular dynamics of DCM development in dystrophinopathies are still unclear. Although this condition involves mostly cardiomyocytes, increasing attention has been directed at understanding the features and progression of DCM in the non-muscular cell fractions. These mainly include cardiac fibroblasts [7-9] and endothelial 
cells [10-13], which are, in part, known to affect extracellular matrix and vascular remodeling. Other stromal cells possibly involved in cardiac homeostasis, survival, and disease dynamics are cardiovascular progenitor cells (CVPC) [14], which include the $\mathrm{CD}_{117^{+}}$(or c-kit)/ $\mathrm{CD} 45^{-}$fraction, and has been the main focus of several recent studies $[15,16]$. Currently, the evidence shows that $\mathrm{c}^{-\mathrm{kit}^{+}} / \mathrm{CD} 45^{-}$are activated by cardiac injury [17] supporting the hypothesis of paracrine regulation of cardiac function under pathophysiological conditions [16, $18,19]$; however, their role and fate in the human heart remains to be elucidated.

Here we describe the first comparative characterization of c-kit ${ }^{+} / \mathrm{CD} 45^{-} \mathrm{CVPC}$ occurrence and tissue plasticity in myocardium obtained during a rare case of a BMD heart transplant in our center, and only the third such transplantation in the Czech Republic during the past three decades of the transplantation program [20]. This unique sample from our BMD patient was compared to healthy control cardiac samples from healthy heart donors for cardiac transplantation.

\section{Results}

\section{Patients' history}

A patient with muscular dystrophy developed mild diseaserelated symptoms at the age 9 yrs. and Gowers' sign was pronounced by the age 15 ; additionally, there was calf pseudohypertrophy. To this day (age 48), the patient does not require a wheelchair and has no signs of intellectual impairment (for recent neurological report, see Additional file 1: Supplementary materials). Slowly progressing cardiomyopathy was detected in 2004 (age 33) and an internal cardiac defibrillator (ICD) was implanted in 2012 (the ICD was magnetic resonance incompatible, and no MRI scans could be performed). In 2014, the patient presented with heart failure. A cardiac evaluation found a reduced left ventricular ejection fraction (15\%) with severe mitral regurgitation (3rd degree, hemodynamically graded as moderate for echo visualization; for a detailed description see Additional file 1: Supplementary materials and Additional file 2: Video 1; Additional file 3: Video 3; Additional file 4: Video 4), and borderline pulmonary hypertension, all of which responded to pharmacological intervention. Ischemic cardiomyopathy was excluded using coronary angiography (see Additional file 1: Supplementary materials). Due to progressive worsening of dyspnea up to the point of pulmonary edema, which required repeated hospital admissions, the patient was put on the non-urgent heart transplantation waiting list. The prescribed heart failure medication included betablockers, loop and mineralocorticoid diuretics, digoxin, angiotensin-converting enzyme (ACE) inhibitors, and proton pump inhibitors. A bicaval orthotropic cardiac transplantation took place shortly before the patient turned 44 .
He was discharged to out-patient care and follow-up 18 days post-transplantation. During the patient's procedure and the five subsequent heart transplant procedures, surgically available left atrial (LA) tissue, from LA reductions (i.e., surgically required LA shaping and reductions in order to fit the transplant to the left atria of the recipient), were collected for use as healthy controls for this study.

The patient had been screened for genetic mutations, in his twenties, i.e., exon sequencing of the $D M D$ gene, but no known mutations were found. Due to the evident clinical presentation, other genes were not screened. A single point mutation c.3328 G > T, (p. Glu1110X) in exon 25 , causing a stop codon, was later identified in a sample from the patient's first-degree cousin, which was done as part of a family pedigree (see Fig. 1). The patient was subsequently diagnosed with the same mutation. This mutation would normally result in a DMD phenotype. Nevertheless the BMD phenotype of our patient, with a similar stop codon mutation in exon 25 , was explained by the presence of alternatively spliced mRNA, in which a deletion bridges the non-sense mutation and thus partially suppresses its effect [21]. The patient has

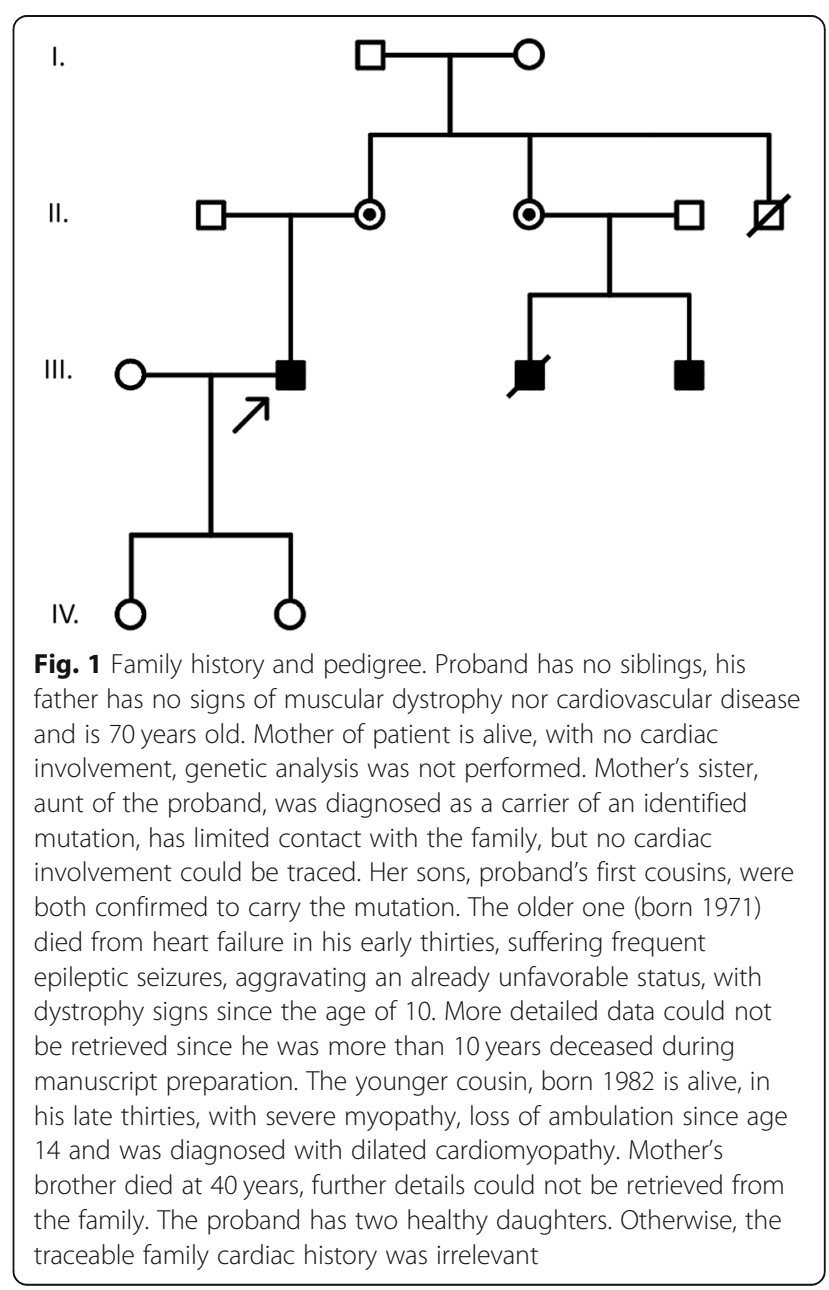


daughters, however, cascade mutation screening was not performed among female relatives, based on their preference. Creatine kinase (CK) levels before transplantation were only mildly increased, oscillating between 20 and $30 \mu \mathrm{kat} / \mathrm{l}$ (reference value under $3.17 \mu \mathrm{kat} / \mathrm{l}$ ); the CK muscle brain (CK-MB) fraction was increased between 0.8-0.9 $\mu \mathrm{kat} / \mathrm{l}$, which normalized after transplantation (under $0.4 \mu \mathrm{kat} / \mathrm{l}$ ). A skeletal muscle biopsy was not performed since the diagnosis was genetically verified.

\section{Gross pathologic description of BMD heart}

The heart explant (size $150 \times 120 \times 70 \mathrm{~mm}$ ) presented bilateral atrial and ventricular dilatation. Both coronary arteries showed sporadic fibrous and atheromatic plaques, without stenosis, and without perivascular inflammation. The wall thickness of the right ventricle (RV) was $4 \mathrm{~mm}$ along the anterior basal side and 3 $\mathrm{mm}$ along the posterior apical side. RV outflow was partially obstructed by a left ventricle (LV) septal mass. The ventricle walls presented with irregular fibrosis, a thinned or absent myocardial layer, and thickened or prevalent adipose tissue. The LV posterior wall, in particular, was irregularly thick, with the subvalvular wall being $5 \mathrm{~mm}$ with a non-compaction appearance (the non-compacted/spongiotic layer: compacted layer ratio was approximately 1 ). The middle part of the LV posterior wall had a thickness of 8 $\mathrm{mm}$, with fibrosis and thinning toward the apex. The anterior LV wall was irregularly thick $(5-10 \mathrm{~mm})$ with focal fibrosis. The IVS thickness was $12 \mathrm{~mm}$. A myxoid transformation of the tricuspid and mitral valves was observed. Histologically, there were partial and non-specific myocardial changes, i.e., dilated cardiomyopathy with hypertrophic cardiomyocytes and interstitial fibrosis. The free LV wall had foci of noncompaction, prominent adipose tissue, and small residual groups of cardiomyocytes. Similar changes were seen in the LV papillary muscles and the RV outflow tract. Laminar fibrosis was present mostly in the subepicardial and middle layers of the compact myocardium regions. Cardiomyocytes showed no signs of acute regressive changes, nor the pathologic changes typical of storage disorders. A slight focal intimal thickening with sporadic incipient atheromatic plaques was found in the coronary arteries.

BMD samples were compared with myocardial samples from hearts explanted due to ischemic heart disease. The controls showed more or less diffuse membranous dystrophin staining. The BMD patient's samples showed a mosaic pattern with an absence of membranous staining and only sporadic isolated myocytes $(<0.1 \%)$ with partial and weak membranous staining. These immunohistopathological findings are shown in Fig. 2.

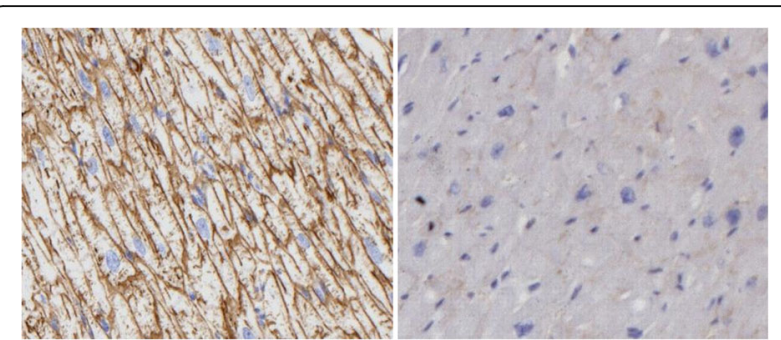

Fig. 2 Immunohistopathology of human myocardium stained for presence of dystrophin. Left image: healthy ventricular myocardium showing membranous aggregation of dystrophin. Right image: Becker muscular dystrophy-affected ventricular myocardium, showing weak membranous distribution of dystrophin. Magnification 400X

\section{C-kit ${ }^{+} / \mathrm{CD}^{-} 5^{-}$cells are depleted in BMD-affected myocardium}

We quantified the number of $\mathrm{c}-\mathrm{kit}^{+} / \mathrm{CD} 45^{-}$cells to detect significant alterations in the cardiac c-kit ${ }^{+} / \mathrm{CD} 45^{-}$population fraction in heart tissue affected by BMD-DCM. Tissue samples from myocardium were dissociated, and single-cell suspensions were quantified with anti-CD117 (c-kit) and anti-CD45 fluorophore-conjugated antibodies. Tissue samples were excised from the whole myocardium of the explanted BMD heart (i.e., LA, right atrium (RA), LV, RV, and intraventricular septum (IVS)) and compared to LA samples of healthy heart donors (HD). While the HD atrial samples contained an average of $1.54 \%$ (1.39; 1.62, and $1.62 \%$ for each HD sample) $\mathrm{c}-\mathrm{kit}^{+} / \mathrm{CD} 45^{-}$cells, samples from the BMD myocardium contained 0.28 and $0.35 \% \mathrm{c}-\mathrm{kit}^{+} / \mathrm{CD} 45^{-}$cells (RA and LA, respectively; see Fig. 3a top row), which was less than a quarter of the HD average. The BMD ventricular samples contained 0.42 ,

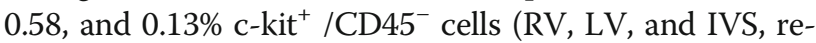
spectively; see Fig. 3a bottom row). The BMD c-kit ${ }^{+}$ $\mathrm{CD} 45^{-}$mean fraction was significantly lower with respect to the mean value of the HD atrial samples $(p=0.036$, calculated using the Mann-Whitney statistical test, Fig. 3b).

\section{BMD heart tissue shows ex vivo reduced plasticity and phase-bright cells resilience}

We evaluated the ability of mildly dissociated tissue explants $\left(<1 \mathrm{~mm}^{3}\right.$ pieces) to adhere to culture dishes, in order to prove their ability to retain tissue plasticity. While BMD explants samples required 7 days of ex-vivo cultivation before starting to attach, the HD samples started to attach within 4 days. We then observed and evaluated cardiac fibroblast cell migration from 19 HD and 13 BMD explants-derived samples to estimate the remodeling capacity of the original tissue. The maximal migration distance of fibroblasts from the explant border after 9 days in vitro was $1031.2 \pm 351.2 \mu \mathrm{m}$ in HD samples, but only $330.9 \pm 224.4 \mu \mathrm{m}$ in BMD $(p<0.001$, Mann-Whitney, Fig. 3c and d top row). We later observed phase-bright 


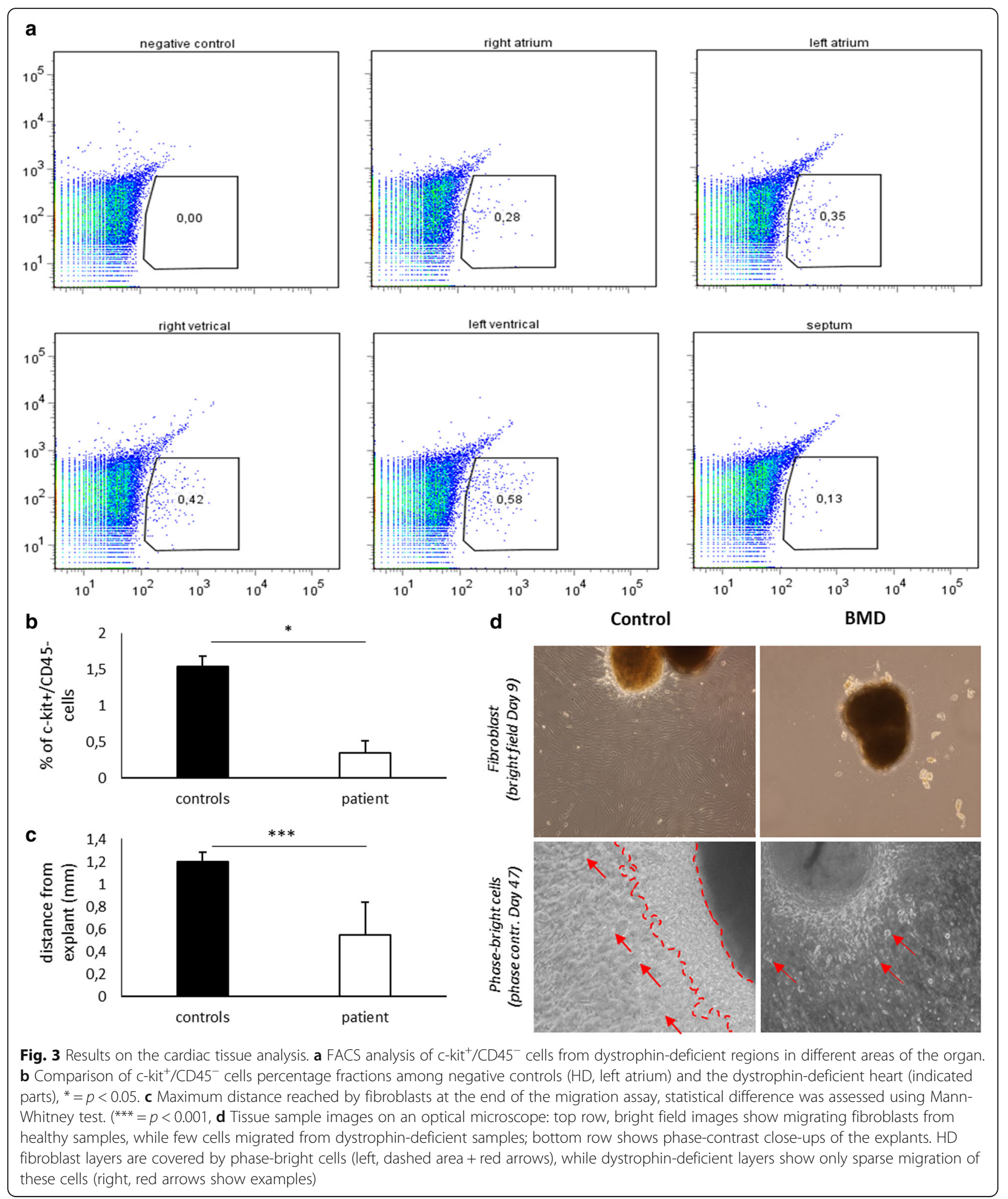

cells on fibroblasts. Phase-bright cells have been previously reported to contain a c-kit ${ }^{+}$fraction [22]. These loosely adherent cells were thus stained for the presence of the c-kit marker, which revealed a $61 \pm 20 \%$ positive fraction (6 explant samples analyzed, see Additional file 1: Supplementary materials). Phase-bright cells in HD samples started to appear on the fibroblast layer after 9 days in vitro. In contrast, phase-bright cells in BMD samples 
only appeared on fibroblasts after 28 days. BMD explants showed few isolated phase-bright cells on the surrounding fibroblast layer, while HD sample had a dense covering on the surrounding explant tissue (Fig. 3D bottom row). Overall, $32.45 \%(37 / 114)$ of the HD explants showed phase-bright cells, while only $15.64 \%$ (23/147) of BMD samples showed phase-bright cells. After 90 days, the HD phase-bright cells had grown enough to allow immunolabelling. The BMD phase-bright cells started to disappear before reaching the quantity necessary for immunolabeling and were no longer observable after 51 days of cultivation, which impaired the comparative analysis.

\section{Discussion}

Heart failure due to DCM is a common clinical manifestation in patients with BMD [5]. It has been shown that CVPCs, including $\mathrm{c}-\mathrm{kit}^{+} / \mathrm{CD} 45^{-}$cells, are involved in cardiac injury and degeneration [17, 23], resulting, for example, in capillary rarefaction, fibrosis, and other pathogeneses of an affected heart [24, 25]. The pathogenesis of dystrophinopathy was previously linked to increased DNA damage and to increased mutagenesis in pluripotent stem cells reprogrammed from DMD patients and lacking dystrophin, as we showed previously [26]. This could affect different organ tissue stem cells or niche supporting cells similar to satellite cells [27]. In this study, we investigated the presence of CVPCs in one model BMD-affected myocardium, as well as tissue remodeling capabilities. We observed that the CVPC fraction found in the dystrophic LA was more than four times lower than the average found in $\mathrm{HD}$ samples. The detected values of BMD c-kit ${ }^{+} / \mathrm{CD} 45^{-}$ fractions were also comparable to previously reported numbers in idiopathic DCM [28]. This CVPCs depletion resembles DCM associated with accelerated aging [29] and can be caused by an increased turnover concomitant with cell damage. These mechanisms of depletion have been shown, for instance, in hematopoietic stem cells with mutated Sirt1 [30], or dystrophin-deficient $\mathrm{ckit}^{+} / \mathrm{CD} 45^{-}$in the GRMD dog model [31]. The reduced tissue plasticity in our model, observed through decreased adherence and cell migration from diseased tissue, also might point to impaired remodeling properties of the BMD-DCM heart. In concert with this hypothesis, only one-tenth of the BMD tissue fragments adhered to gelatin-coated culture dishes, which was almost three-times less than for HD tissue. Dystrophic samples also required nearly twice as much time to attach. Decreased culture dish adherence of BMD heart explanted tissue was accompanied by reduced migration ability of the outgrowing cells. Such behavior could originate in the presence of an activated myofibroblast subpopulation, due to a chronic state of myocardial injury and inflammation [32] with progressive fibrosis [33, 34]. Myofibroblasts are a specialized cell type in between the phenotype of cardiac fibroblasts and smooth muscle myocytes that express $\alpha$-smooth muscle actinin (SMA) and play an important role in cardiac remodeling [35, 36]. Their motility is reduced due to overexpression of focal adhesion proteins [37] and reduced production of collagen VIII, the lack of which has been associated with decreased migratory abilities [38]. Thus, the presence of terminally differentiated myofibroblasts might explain the reduced adhesion and migration of the cells in vitro.

Ultimately, impaired survival rate of phase-bright cells in BMD samples was observed, while these cells appeared and persisted in the HD fibroblast layer. Moreover, in the BMD samples they were only sparsely identifiable and prematurely disappeared from the BMD fibroblast layer. Their limited in vitro survival in dystrophin-deficient heart explants might hint at altered c-kit ${ }^{+} / \mathrm{CD} 45^{-}$cell resilience also in vitro and subsequently could promote BMD-DCM progression.

The main limitation of the study is the unique characteristic of the human BMD heart sample since only one specimen was available and opportunities to study a heart affected by dystrophinopathy are extremely rare. A comparable sampling of healthy human ventricular tissue was impossible and clearly unethical; thus, atrial tissue controls came from transplants, considered healthy from a cardiac point of view and thus suitable for heart transplantation. We chose donors of similar age to the BMD patient to remove the age bias; with one exception, all were males. Still, tissue availability was limited with only minimal information regarding the medical backgrounds of the donors and families.

In non-ischemic DCM, LA remodeling was observed in functional and morphological changes [39], making this heart area a valid control source. The wide age interval of the donor cohort (see Additional file 1: Supplementary materials) is common in other similar studies [28], and was not significantly different from the age of the BMD patient, as shown using the one-sample ttest $(p=0.625)$. To the best knowledge of the authors, this analysis is the first to directly quantify c-kit ${ }^{+} / \mathrm{CD} 45^{-}$ cells from BMD-DCM heart tissue. It contributes to the present understanding of the occurrence and role of c$\mathrm{kit}^{+} / \mathrm{CD} 45^{-}$cells by showing a comparative reduction in this cell fraction, which can be correlated with reduced plasticity and cellular resilience in the BMD heart.

\section{Conclusions}

Our findings give further insights into the correlation between c-kit ${ }^{+} / \mathrm{CD} 45^{-}$CVPCs levels, irreversible remodeling, and heart failure in BMD. Future studies aimed at describing $\mathrm{c}-\mathrm{kit}^{+} / \mathrm{CD} 45^{-}$mechanisms of activation, paracrine modulation, and genetic impairment can provide new therapeutic perspectives into the management of cardiomyopathies. The analysis of $\mathrm{c}-\mathrm{kit}^{+} / \mathrm{CD} 45^{-}$cells or possibly their secretome might serve as a helpful biomarker for early 
stages of cardiomyopathy, possibly not limited only to BMD patients.

\section{Methods \\ Flow cytometry assay}

Tissue samples were excised (in BMD) or extracted during a left atrial biopsy (from heart donors HD). Reduced dystrophin expression was confirmed by immunohistochemistry of myocardial samples. BMD samples were taken from different sections of the heart (left and right atrium, left and right ventricle, and the interventricular septum). As for the healthy donors, only adult patients were included (age 24-62 years, variance statistically insignificant $p=0.625$ ) to exclude the bias of pediatric patients that have increased CVPC levels [23]. Due to the unavailability of ventricular samples, only atrial samples, which were obtained from surgical reduction before placing the healthy heart into the chest cavity during transplantations, were used. No other differences in CVPC levels were reported. Samples were treated as previously described by Messina et al. [22]. Briefly, tissue samples were immersed in a $60 \mathrm{~mm}$ Petri dish (TPP, Trasadingen, $\mathrm{CH}$ ) filled with $1 x \mathrm{PBS}+2 \%$ Pen/Strep (BioSera, Nuaille, France) and cut into $1-2 \mathrm{~mm}^{3}$ pieces with scissors. Tissue fragments were digested in a dissociating solution composed of $0.1 \%$ Collagenase IV in DMEM-F12 (both from Life Technologies, Carlsbad, CA, USA). Dissociation was carried out for $2 \mathrm{~h}$ at $37^{\circ} \mathrm{C}$ with gentle manual agitation every 15 mins. The dissociation was stopped by adding an equal volume of explant IMDM medium (Life Technologies) supplemented with FBS $10 \%$ (Life Technologies), $\beta$ mercaptoethanol 1\% (SigmaAldrich, St. Louis, MO), Pen/Strep 1\%, and L-glutamine $1 \%$ (both from BioSera). Samples were collected and pipetted vigorously with a $1 \mathrm{ml}$ tip to release cells from tissue blocks. The dissociated cell suspension was filtered through a $40 \mu \mathrm{m}$ strainer (Costar, Washington DC, USA) and spun in a conical tube at $200 \times \mathrm{g}$ for $5 \mathrm{~min}$. The supernatant was removed, and the cell pellet was resuspended in FACS-PBS, made from 1xPBS with 0.5\% BSA (Sigma Aldrich) and $2 \mathrm{mM}$ EDTA (Penta, Prague, $\mathrm{CZ}$ ). Spinning and resuspension were repeated 3 times to ensure enzyme removal and cell separation. Antibodies were finally added to the suspension (CD45FITC, cl. 30F11; CD117-APC, cl.3C11, all from Miltenyi Biotech, Bergisch Gladbach, DE) and the analysis was run on a BD FACS Canto II (BD Biosciences, New Jersey, NJ-USA). The negative control for FACS was an unlabeled cell suspension. Data were analyzed using FlowJo (FlowJo LLC, Ashland, OR-USA).

\section{Cell migration assay and immunocytochemistry}

Samples were cut into $1-2 \mathrm{~mm}^{3}$ pieces, as described in the previous paragraph. For the migration assay and c- $\mathrm{kit}^{+} / \mathrm{CD} 45^{-}$cell cultivation, the tissue explants were collected in a dissociation solution and incubated for 5 mins at $37^{\circ} \mathrm{C}$. The enzymatic solution was then removed and replaced with a fresh solution. Incubation and enzyme replacement was repeated three times. Dissociation was stopped by adding an equal volume of explant medium. The samples were spun at $200 \times \mathrm{g}$ for $2 \mathrm{~min}$, then resuspended with explant medium. The tissue explants were distributed evenly on a $0.1 \%$ gelatin-treated 6-well plates (TPP), in $5 \mathrm{ml}$ of explant medium. The dishes were not moved for 4 days to allow attachment of the tissue. The medium was changed every 4 days, and photos were taken on the same days using an inverted Olympus IX71 microscope (Tokyo, Japan), and QuickPhoto Camera software (Promicra, Prague, CZ). Pictures were analyzed using ImageJ open-source software to measure migration [40] distance and phase-bright cells. C-kit+ cells were detected using CD117-APC (Miltenyi Biotec, Bergisch Gladbach, $\mathrm{DE}$ ) dissolved in 1:100 proportion in IMDM $+0.5 \%$ BSA. Photos were taken using a Zeiss LSM700 confocal laser scanning microscope (Zeiss, Oberkochen, DE).

\section{Histopathological methods}

The heart explants were dissected according to standard procedures, samples were taken from right atrium, tricuspid valve; the anterior and posterior wall, and outflow tract of the right ventricle; the right coronary artery; the right atrium and mitral valve; anterior papillary muscles; multiple samples from the anterior and posterior wall of the left ventricle; the septum and left coronary arteries. For immunehistological identification of dystrophin, formalin-fixed, paraffin-embedded tissue sections were treated with heat antigen retrieval $\left(95^{\circ} \mathrm{C}\right.$ for $45 \mathrm{~min}, \mathrm{pH}$ 9), and then treated with primary antibodies (Dystrophin Mouse Monoclonal Antibody, Leica, clone 34C5) using the avidin-biotinimmunoperoxidase method according to the manufacturer's protocol.

\section{Statistical analysis}

Descriptive statistics and comparisons between sample groups were performed using Prism 5.0 software (GraphPad, La Jolla, CA-US). Available normality tests were performed, and the non-parametric Mann-Whitney test was used to estimate statistical differences between samples. A $p$-value less than 0.05 was considered significant.

\section{Supplementary information}

Supplementary information accompanies this paper at https://doi.org/10. 1186/s13023-019-1257-4.

Additional file 1. Supplementary materials.

Additional file 2: Video 1. Coronarography - right coronary artery.

Additional file 3: Video 2. Coronarography - left coronary artery.

Additional file 4: Video 3. Echocardiography. 


\section{Abbreviations}

BMD: Becker muscular dystrophy; DCM: Dilated cardiomyopathy; HTx: Heart transplantation; IVS: Interventricular septum; LV: Left ventricle; PBC: Phasebright cells; RV: Right ventricle

\section{Acknowledgements}

The authors would like to thank geneticist Dr. Gaillyova and attending neurologists Dr. Vohanka and Dr. Peslova for assistance in clarifying the available documentation.

\section{Authors' contributions}

MP was responsible for the design of the study and the coordination, conducted clinical follow-up of the patient, and obtained the informed consent as well as the collection of samples. SJ was responsible for the cellular laboratory sample preparation, the cellular experiments, and their evaluation. GC was responsible for results collection, drafting the manuscript, and figures preparation. $\mathrm{MH}$ and JK were attending the cardiologists of the patient. PN was responsible for the surgical preparation of the samples during heart transplantation and the surgeon on the case. AK performed part of the ex vivo analysis of the samples. VZ provided the histological examination of the dystrophic heart samples. PD and VR secured funding of the project and supervised the production of the results and the manuscript. All authors read and approved the final manuscript.

\section{Funding}

This work was supported by the Ministry of Education, Youth, and Sports of the Czech Republic (7AMB13FR011, No. CZ.02.1.01/0.0/0.0/16_019/0000868, projects no. LQ1605 and no. LQ1601 from the National Program of Sustainability II) and supported by funds from the Faculty of Medicine MU to junior researchers Martin Pesl and Sarka Jelinkova.

\section{Availability of data and materials}

The data that support the findings of this study are available from the corresponding author V.R. upon reasonable request.

\section{Ethics approval and consent to participate}

This study was carried out in accordance with the recommendations of the Masaryk University Ethics Committee and St. Ann's University Hospital Ethics Committee, issuing approval nr. 51 V/2015 - approved consent for heart tissue sampling and analysis, and genetic information analysis (DNA and circulating free DNA), protocol was approved on 12th August 2015. The "healthy donor" (HD) control samples were obtained from donors diagnosed with brain death. The hearts were brought to the transplantation center for transplantation and were provided for scientific analysis after the anonymization of donor data. Thus, individual information, such as names of donors, was not available to investigators. Samples from deceased donors were not further addressed by the ethics committee since the transplantation system is opt-out according to the law 285/2002 Sb. in the Czech Republic. At the same time, due to anonymization, family members were not reachable.

\section{Consent for publication}

The study subject gave written informed consent regarding explanted organ sampling and publication of results.

\section{Competing interests}

The authors declare that they have no competing interests.

\section{Author details}

${ }^{1}$ Department of Biology, Faculty of Medicine, Masaryk University, Kamenice 5, Brno 62500, Czech Republic. ${ }^{2}$ International Clinical Research Center, (ICRC), St. Anne's University Hospital, Pekarska 53, Brno 65691, Czech Republic. ${ }^{3} 1$ st Department of Cardiovascular Diseases, St. Anne's University Hospital and Masaryk University, Pekarska 53, Brno 65691, Czech Republic. ${ }^{4}$ Central European Institute of Technology (CEITEC MU), Nanobiotechnology, Kamenice 5, Brno 62500, Czech Republic. ${ }^{5}$ Department of Cardiology, University Hospital Brno, Jihlavska 20, Brno 62500, Czech Republic. ${ }^{6}$ Center for Cardiovascular Surgery and Transplantation, Pekarska 53, Brno 65691, Czech Republic. ${ }^{7} 1$ st Department of Pathology, Faculty of Medicine, Masaryk University and St. Anne's University Hospital in Brno, Pekarska 53, Brno 65691, Czech Republic.
Received: 23 July 2019 Accepted: 19 November 2019

Published online: 05 March 2020

\section{References}

1. Ho R, Nguyen M-L, Mather P. Cardiomyopathy in Becker muscular dystrophy: overview. World J Cardiol. 2016;8:356.

2. Yilmaz A, Gdynia H-J, Baccouche H, Mahrholdt H, Meinhardt G, Basso C, et al. Cardiac involvement in patients with Becker muscular dystrophy: new diagnostic and pathophysiological insights by a CMR approach. J Cardiovasc Magn Reson. 2008;10:50.

3. Panovský R, Pešl M, Holeček T, Máchal J, Feitová V, Mrázová L, et al. Cardiac profile of the Czech population of Duchenne muscular dystrophy patients: a cardiovascular magnetic resonance study with T1 mapping. Orphanet J Rare Dis. 2019;14:10.

4. Finsterer J, Stöllberger C. Cardiac involvement in Becker muscular dystrophy. Can J Cardiol. 2008;24:786-92.

5. Papa AA, D'Ambrosio P, Petillo R, Palladino A, Politano L. Heart transplantation in patients with dystrophinopathic cardiomyopathy: review of the literature and personal series. Intractable Rare Dis Res. 2017;6:95-101.

6. Darras BT, Miller DT, Urion DK. Dystrophinopathies. Seattle: University of Washington; 1993. http://www.ncbi.nlm.nih.gov/pubmed/20301298.

7. Furtado MB, Nim HT, Boyd SE, Rosenthal NA. View from the heart: cardiac fibroblasts in development, scarring and regeneration. Development. 2016; 143:387-97.

8. Furtado MB, Costa MW, Pranoto EA, Ekaterina S, Pinto Alexander R, Lam Nicholas T, et al. Cardiogenic genes expressed in cardiac fibroblasts contribute to heart development and repair. Circ Res. 2014;114:1422-34.

9. Lajiness JD, Conway SJ. The dynamic role of cardiac fibroblasts in development and disease. J Cardiovasc Transl Res. 2012;5:739-48.

10. Talman V, Kivelä R. Cardiomyocyte-endothelial cell interactions in cardiac remodeling and regeneration. Front Cardiovasc Med. 2018;5. https://doi.org/ 10.3389/fcrm.2018.00101.

11. Mathison M, Rosengart TK. Heart regeneration: the endothelial cell comes first. J Thorac Cardiovasc Surg. 2018;155:1128-9.

12. Hui Z, Lui Kathy O, Bin Z. Endocardial cell plasticity in cardiac development, diseases and regeneration. Circ Res. 2018;122:774-89.

13. Gray G, Toor I, Castellan R, Crisan M, Meloni M. Resident cells of the myocardium: more than spectators in cardiac injury, repair and regeneration. Curr Opin Physiol. 2018;1:46-51.

14. Leong YY, Ng WH, Ellison-Hughes GM, Tan JJ. Cardiac stem cells for myocardial regeneration: they are not alone. Front Cardiovasc Med. 2017;4. https://doi.org/10.3389/fcrm.2017.00047.

15. Zhou B, Wu SM. Reassessment of c-kit in cardiac cells: a complex interplay between expression, fate, and function. Circ Res. 2018;123:9-11.

16. Hodgkinson CP, Bareja A, Gomez JA, Dzau VJ. Emerging concepts in paracrine mechanisms in regenerative cardiovascular medicine and biology. Circ Res. 2016;118:95-107.

17. Finan A, Demion M, Sicard P, Guisiano M, Bideaux P, Monceaux K, et al. Prolonged elevated levels of c-kit+ progenitor cells after a myocardial infarction by beta 2 adrenergic receptor priming. J Cell Physiol. 2019;234: 18283-96.

18. Hong KU, Guo Y, Li Q-H, Cao P, Al-Maqtari T, Vajravelu BN, et al. c-kit+ Cardiac stem cells alleviate post-myocardial infarction left ventricular dysfunction despite poor engraftment and negligible retention in the recipient heart. PLOS ONE. 2014;9:e96725.

19. Davis DR. Cardiac stem cells in the post-Anversa era. Eur Heart J. 2019;40: 1039-41.

20. Viklicky O, Fronek J, Trunecka P, Pirk J, Lischke R. Organ transplantation in the Czech Republic. Transplantation. 2017;101:2259.

21. Fajkusová L, Lukáš Z, Tvrdíková M, Kuhrová V, Hájek J, Fajkus J. Novel dystrophin mutations revealed by analysis of dystrophin mRNA: alternative splicing suppresses the phenotypic effect of a nonsense mutation. Neuromuscul Disord. 2001;11:133-8.

22. Messina E, De Angelis L, Frati G, Morrone S, Chimenti S, Fiordaliso F, et al. Isolation and expansion of adult cardiac stem cells from human and murine heart. Circ Res. 2004;95:911-21.

23. Matuszczak S, Czapla J, Jarosz-Biej M, Wiśniewska E, Cichoń T, Smolarczyk R, et al. Characteristic of c-kit+ progenitor cells in explanted human hearts. Clin Res Cardiol Off J Ger Card Soc. 2014;103:711-8.

24. Lombardi R, Chen SN, Ruggiero A, Gurha P, Czernuszewicz GZ, Willerson JT, et al. Cardiac fibro-adipocyte progenitors express desmosome proteins and 
preferentially differentiate to adipocytes upon deletion of the desmoplakin gene. Circ Res. 2016;119:41-54.

25. Kazakov A, Laufs U. Healthy and unhealthy cardiac progenitor cells modify the pathogenesis of myocardial diseases. Circ Res. 2016;119:10-2.

26. Jelinkova S, Fojtik P, Kohutova A, Vilotic A, Marková L, Pesl M, et al. Dystrophin deficiency leads to genomic instability in human pluripotent stem cells via NO synthase-induced oxidative stress. Cells. 2019;8(1):53.

27. Dumont NA, Wang YX, von Maltzahn J, Pasut A, Bentzinger CF, Brun CE, et al. Dystrophin expression in muscle stem cells regulates their polarity and asymmetric division. Nat Med. 2015;21:1455-63.

28. Matuszczak S, Czapla J, Jarosz-Biej M, Winiewska E, Cichoń T, et al. Characteristic of c-Kit + progenitor cells in explanted human hearts. Clin Res Cardiol. 2014;103(9):711-8. https://doi.org/10.1007/s00392-014-0705-3.

29. Saheera S, Nair RR. Accelerated decline in cardiac stem cell efficiency in spontaneously hypertensive rat compared to normotensive Wistar rat. PLoS One. 2017;12:e0189129

30. Rimmelé P, Bigarella CL, Liang R, Izac B, Dieguez-Gonzalez R, Barbet G, et al. Aging-like phenotype and defective lineage specification in SIRT1-deleted hematopoietic stem and progenitor cells. Stem Cell Rep. 2014;3:44-59.

31. Cassano M, Berardi E, Crippa S, Toelen J, Barthelemy I, Micheletti R, et al. Alteration of cardiac progenitor cell potency in GRMD dogs. Cell Transplant. 2012;21:1945-67.

32. Kharraz Y, Guerra J, Pessina P, Serrano AL, Muñoz-Cánoves P. Understanding the process of fibrosis in Duchenne muscular dystrophy. Biomed Res Int. 2014;2014:965631.

33. Mann CJ, Perdiquero E, Kharraz Y, Aguilar S, Pessina P, Serrano AL, et al. Aberrant repair and fibrosis development in skeletal muscle. Skelet Muscle. 2011;1:21.

34. Fan D, Takawale A, Lee J, Kassiri Z. Cardiac fibroblasts, fibrosis and extracellular matrix remodeling in heart disease. Fibrogenesis Tissue Repair. 2012;5:15.

35. Dostal D, Glaser S, Baudino TA. Cardiac fibroblast physiology and pathology. In: Terjung R, editor. Comprehensive physiology. Hoboken: John Wiley \& Sons, Inc.; 2015. p. 887-909. https://doi.org/10.1002/cphy.c140053.

36. Li L, Zhao Q, Kong W. Extracellular matrix remodeling and cardiac fibrosis. Matrix Biol. 2018;68-69:490-506.

37. Santiago J-J, Dangerfield AL, Rattan SG, Bathe KL, Cunnington RH, Raizman $\mathrm{JE}$, et al. Cardiac fibroblast to myofibroblast differentiation in vivo and in vitro: expression of focal adhesion components in neonatal and adult rat ventricular myofibroblasts. Dev Dyn. 2010;239:1573-84.

38. Skrbic B, Engebretsen KVT, Strand ME, Lunde IG, Herum KM, Marstein HS, et al. Lack of collagen VIII reduces fibrosis and promotes early mortality and cardiac dilatation in pressure overload in mice. Cardiovasc Res. 2015;106:32-42.

39. Hoit BD, Ohio C. Left atrial size and function role in prognosis. J Am Coll Cardiol. 2014;63:493-505.

40. Treloar KK, Simpson MJ. Sensitivity of edge detection methods for quantifying cell migration assays. PLoS One. 2013;8:e67389.

\section{Publisher's Note}

Springer Nature remains neutral with regard to jurisdictional claims in published maps and institutional affiliations.

Ready to submit your research? Choose BMC and benefit from:

- fast, convenient online submission

- thorough peer review by experienced researchers in your field

- rapid publication on acceptance

- support for research data, including large and complex data types

- gold Open Access which fosters wider collaboration and increased citations

- maximum visibility for your research: over $100 \mathrm{M}$ website views per year

At $\mathrm{BMC}$, research is always in progress.

Learn more biomedcentral.com/submissions 